\title{
ANÁLISE PERCEPTUAL DOS LOGOTIPOS DAS 10 PRINCIPAIS ONGS DE MEIO AMBIENTE DO BRASIL: UM ESTUDO NOS ATRIBUTOS DE ATRATIVIDADE E REPRESENTATIVIDADE
}

\author{
Vagner Sérgio Custódio ${ }^{1}$ \\ Maria Fernanda Sanchez Maturana ${ }^{2}$ \\ Fabio Luciano Violin ${ }^{3}$
}

\begin{abstract}
RESUMO
Logotipos possuem o objetivo de divulgar empresas, expondo a ideia embutida na sua concepção, para isto, o profissional criador precisa ter um pré-conhecimento da temática que será exibida, além de utilizar ferramentas atrativas e representativas. Análises perceptuais realizadas com o público-alvo podem ser elementos contribuintes nesta criação. Desta forma, este artigo teve o objetivo de realizar a análise em logotipos das 10 principais Organizações não governamentais ambientais brasileiras (ONGs), visto que, essas instituições são fundamentais na contribuição da educação ambiental para a minimização de impactos. Para isto, realizou-se testes psicofísicos escalares perceptuais de categoria e magnitude nos atributos atratividade e representatividade. Estes testes foram aplicados em 25 pessoas, sendo docentes e discentes do curso de bacharelado em Turismo da Universidade Estadual Paulista. Os logotipos foram retirados do website ambiental Ideias Green, no qual, elencouse as seguintes ONGs: (1 - SOS Mata Atlântica; 2 - Recicloteca; 3 - Ecoa; 4 - Amazônia; 5 - Ecoar; 6 - Intituto Akatu; 7 - WWF Brasil; 8 - ISA; 9 - Greenpeace; 10 - Conservação Internacional Brasil). Os resultados finais que englobam todos os quesitos analisados mostraram que a ONG SOS Mata Atlântica teve a primeira colocação e a ONG Greenpeace a segunda. Conclui-se que, muitas pessoas não conhecem as diferenças dos termos analisados, além de que a percepção engloba elementos que vão além do que é visível nos logotipos, principalmente por serem influenciados por quesitos de um conhecimento anterior, comprovando assim a teoria inicial. Ou seja, os logotipos com melhores colocações são os mais conhecidos na temática ambiental.
\end{abstract}

PALAVRAS-CHAVE: Logotipos. ONGs. Meio Ambiente.

\section{ANALYSIS OF PERCEPTUAL LOGOS OF TOP 10 NGOS MEDIA ENVIRONMENT BRAZIL : A STUDY IN ATTRACTIVENESS ATTRIBUTES AND STANDING}

\footnotetext{
${ }_{1}^{1}$ Professor Doutor, Universidade Estadual Paulista, vagner@rosana.unesp.br

${ }^{2}$ Graduanda do Curso de Turismo, Universidade Estadual Paulista, ma.fersanchez@hotmail.com

${ }^{3}$ Professor Mestre, Universidade Estadual Paulista, violin@rosana.unesp.br
} 
da Alta Paulista

\begin{abstract}
Logos have the objective of making companies, exposing the embedded idea in its design, for this professional creator must have a pre-knowledge of the subject that appears, besides using attractive and representative tools. Perceptual analysis performed with the target audience may be contributing elements in this creation. Thus, this article aimed to perform the analysis in logos of the top 10 Brazilian environmental non-governmental organizations (ONGs), since these institutions are fundamental in environmental education contribution to the minimization of impacts. For this, there was psychophysical tests scalar perceptual category and magnitude of the attributes attractiveness and representativeness. These tests were applied to 25 people, including teachers and students of the Bachelor in Tourism at the São Paulo State University. The logos were removed from the environmental website Green Ideas, in which the following are listed the ONGs: 1 - SOS Mata Atlântica; 2 - Recicloteca; 3 - Ecoa; 4 - Amazônia; 5 - Ecoar; 6 - Intituto Akatu; 7 - WWF Brasil; 8 ISA; 9 - Greenpeace; 10 - Conservação Internacional Brasil). The final results that include all items analyzed showed that the SOS Mata Atlântica ONG had first place and the ONG Greenpeace second. In conclusion, many people do not know the differences of the terms analyzed, and that perception encompasses elements that go beyond what is visible on the logos, mainly being influenced by questions of prior knowledge, thus proving the initial theory. le logos with better placements are the best known in environmental issues.
\end{abstract}

KEYWORDS: Logos. ONGs. Environment.

\title{
ANÁLISIS DE PERCEPTUAL LOGOS DE TOP 10 ONG MEDIA AMBIENTE -BRASIL: UN ESTUDIO EN ATRACTIVO ATRIBUTOS Y PERMANENTE
}

\begin{abstract}
RESUMEN
Logos tienen el objetivo de hacer de las empresas, la exposición de la idea incrustada en su diseño, para este creador profesional debe tener un conocimiento previo del sujeto que aparece, además de utilizar herramientas atractivas y representativas. Análisis perceptual realizado con el público objetivo puede estar contribuyendo elementos en esta creación. Por lo tanto, este artículo apunta a realizar el análisis en los logos de los 10 principales organizaciones brasileñas ambientales no gubernamentales (ONG), ya que estas instituciones son fundamentales en la contribución de la educación ambiental a la minimización de los impactos. Por esto, no había pruebas psicofísicas escalares categoría perceptual y la magnitud de los atractivos atributos y representatividad. Estas pruebas se aplicaron a 25 personas, entre profesores y alumnos de la Licenciatura en Turismo en la Universidad Estadual Paulista. Los logotipos fueron retirados de las Ideas Verdes sitio web del medio ambiente, en los que los siguientes se enumeran las ONG: 1 - SOS Mata Atlântica; 2 - Recicloteca; 3 - Ecoa; 4 Amazônia; 5 - Ecoar; 6 - Intituto Akatu; 7 - WWF Brasil; 8 - ISA; 9 - Greenpeace; 10 - Conservação Internacional Brasil)Los resultados finales, que incluyen todos los elementos analizados mostraron que el Bosque Atlántico ONG SOS tuvo el primer lugar y el segundo ONG Greenpeace. En conclusión, muchas personas no conocen las diferencias de los términos analizados, y que la percepción abarca elementos que van más allá de lo que es visible en los logos, principalmente siendo influenciado por cuestiones de conocimiento previo, lo que demuestra la teoría inicial. Logotipos le con mejores ubicaciones son las más conocidas en el tema ambiental.
\end{abstract}

PALABRAS-CLAVE: Logos. ONG. Medio Ambiente. 


\section{INTRODUÇÃO}

O uso de logotipos geralmente possui o objetivo de divulgar uma empresa ou instituição, expondo um conjunto de significados embutidos em sua concepção. Para que sua identidade seja repassada corretamente o logotipo deveria ser visivelmente atraente, instigando a pessoa a se interessar pelo assunto exibido e consequentemente pela empresa que o envolve, ou seja, a empresa poderá ser reconhecida pelas suas áreas atuantes. Para isso, ele também precisa ser representativo, para que transmita de fato suas propostas aos observadores.

Os logotipos são desenvolvidos geralmente por designers gráficos, mas, profissionais da mercadologia também podem desenvolvê-lo, especialmente em ralação aos conceitos relacionados a eles. Desta forma, para os logotipos serem atraentes e representativos esses profissionais precisam ter um pré-conhecimento a respeito do processo que envolve a criação.

Entretanto, na realidade dificilmente os logotipos são submetidos a testes perceptuais ao público antes de serem divulgados. Este fato é decorrente da falta de conhecimento das técnicas metodológicas da análise de percepção pelos envolvidos no processo de criação. Desta forma, o profissional com conhecimento técnico é o profissional ideal para analisar os indicadores advindos das reações perceptuais nos testes junto ao público de interesse.

Quando os conhecimentos necessários não são obtidos e nem a aplicação dos testes feita, a probabilidade de a empresa que estiver criando o seu logotipo não ter seus objetivos alcançados é alta. A demanda correta pode não ser atraída, prejudicando a obtenção de clientes, visto que, nas ações de marketing o elemento gráfico é considerado um dos principais meios de convencimento (BARICH; KOTLER, 1991:95).

Esses logotipos muitas vezes são compostos por imagens, formas, e em alguns casos, frases. Outro problema que os envolve refere-se aos termos atratividade e representatividade que podem ser interpretados de diferentes formas, pois quando estes quesitos são analisados em logotipos, outras características podem ser verificadas pelo observador. 
Ser considerado o mais atraente pode ser quando a pessoa acredita que aquele logotipo a chamou mais atenção, pelas formas, pela cor, pelas imagens representadas e até mesmo pelo o que está escrito. $\mathrm{O}$ mesmo acontece com o termo representatividade, na qual cada pessoa pode obter uma interpretação, mas este quesito engloba ainda elementos subjetivos, como o que a imagem e as letras representam em relação ao que aquela empresa quer mostrar (FERREIRA, 1999).

As ONGs (Organizações não governamentais) objeto de estudo desta pesquisa, são voltadas para o terceiro setor, que é composto por organizações sem fins lucrativos com ênfase na participação voluntária, possuem um âmbito não governamental, e são um meio para à incorporação da cidadania, sobretudo às manifestações na sociedade civil (IOSCHPE, 2005).

Ou seja, o terceiro setor agrega instituições de interesse público, mas que são mantidas pela iniciativa privada, sem finalidade lucrativa. Trata-se de um setor que é voltado para uma terceira forma de redistribuição de riqueza, diferente do Estado e do mercado. Além das ONGs outras instituições estão inseridas neste setor, como associações, entidades, fundações, dentre outras (IOSCHPE, 2005).

Neste sentido, Costa (2006) relata que:

O surgimento de cidadãos organizados e a visibilidade de suas

atuações fizeram surgir a sigla ONG, reconhecida internacionalmente e definida pelas Nações Unidas como organizações internacionais que não foram criadas pela via de acordos inter-governamentais. (COSTA, 2006, p. 29).

Entende-se então que uma ONG é constituída pela vontade autônoma, com pessoas que se reúnem para buscar um objetivo comum de forma não lucrativa. As ONGs ambientais surgiram desta forma, com o fim de buscar a preservação da natureza se atentando aos outros âmbitos que se relacionam a ela, como as comunidades, e os patrimônios históricos e culturais do país. Desta forma, as ONGs ambientais realizam projetos, e pesquisas em busca da educação ambiental para que as pessoas possam se conscientizar e contribuir para a preservação do meio ambiente e para o desenvolvimento sustentável em si.

Neste sentido, relata-se que o termo desenvolvimento sustentável seria o equilíbrio entre os âmbitos econômicos, sociais e ambientais que envolvem a sociedade. As primeiras discussões que originaram essa expressão ocorreram em 1972 na primeira Conferência da ONU para o Meio Ambiente Humano, conhecida 
como Conferência de Estocolmo. Entretanto, apenas em 1987 este termo foi definido e publicado no Relatório Nosso Futuro Comum, também conhecido como Relatório Brundtland (VIOLA; LEIS, 2008).

Desde então, outros eventos surgiram para discutirem problemas globais e principalmente de caráter socioambientais, tais como o Rio-92, onde o termo passou a ter mais força e importância (VIOLA; LEIS, 2008).

Desta forma, diante dos inúmeros conceitos, o termo desenvolvimento sustentável, pode ser entendido como "um padrão de transformações econômicas estruturais e sociais que otimizam os benefícios societais e econômicos disponíveis no presente, sem destruir o potencial de benefícios similares no futuro" (BARONI, 1992, p.15).

Considerando que, esses eventos foram importantes no âmbito conceitual, mas que não obtiveram muitos resultados na prática, as ONGs ambientais começaram a ser criadas para produzirem projetos e ações que realmente poderiam contribuir para a minimização de impactos.

As ONGs, desta forma, estão mais próximas da realidade da sociedade, permitindo o envolvimento das comunidades com os problemas que as rodeiam, gerando então estratégias para melhorar a qualidade de vida dessa população.

Neste contexto, relata-se primeiramente que os quesitos básicos de sobrevivência são essenciais para o início de um desenvolvimento sustentável, como o saneamento, a fome, e o desemprego. Sendo assim, as ONGs buscam resolver esses problemas para posteriormente pensarem em ações ambientais específicas. Essas organizações que possuem características ambientais geralmente utilizam a educação ambiental como método para a minimização dos impactos.

Visto isto, a educação ambiental tem: “(...) a tarefa de estimular o desenvolvimento de uma nova consciência a respeito das relações do homem com o seu ambiente, e produzir novas condutas capazes de levar as pessoas a se envolverem com as questões ambientais." (DIAS, 1993, p.02).

Segundo BURSZTYN; BURSZTYN (2013) a preocupação com as questões ambientais no Brasil não era julgada como sendo importante, sendo que as pessoas tinham consciência primitiva em relação a minimização de impactos, mas atualmente após a evolução do capitalismo e a destruição em massa dos recursos 
naturais, a sociedade exige práticas sustentáveis. Com isto, as ONGs podem ser uma ferramenta importante para que as pessoas se insiram e contribuam para este objetivo comum.

Considera-se ainda que, o Governo muitas vezes é incapaz de estar presente efetivamente em todos os problemas que envolvem a comunidade, desta forma, incentivam as organizações não governamentais, tornando-as importantes na gestão pública do país.

No caso das ONGs e seus devidos logotipos, é necessário que o que foi exposto realmente consiga englobar os objetivos propostos por elas, ou seja, principalmente a preservação da natureza e a conscientização imposta nesta ideia. Visto isto, se esses logotipos forem bem elaborados, as pessoas poderão busca-las com mais facilidade, tornando-as mais confiáveis.

Neste sentido, surge a questão: Será que os logotipos das ONGs ambientais brasileiras são considerados atrativos e representativos? A atratividade e representatividade podem estar relacionadas à credibilidade dessas ONGs?

Estes questionamentos são de grande valia, considerando a situação degradante dos ambientes naturais brasileiros que são transformados e impactados constantemente, principalmente pela atividade turística não planejada (BARONI, 1992).

Nesse contexto essa pesquisa, pretendeu contribuir para melhoria na criação visual das ONGs podendo estimular o vinculo da sociedade nestas instituições, além de ser uma proposta metodológica viável em diversas situações na qual necessite analisar a percepção visual nas ações e atividades em geral.

\section{METODOLOGIA}

Esta pesquisa buscou analisar a percepção das pessoas em relação às ONGs ambientais mais importantes do Brasil, com os atributos atratividade e representatividade. Para isto, usou-se o website www.ideiasgreen.com.br, que publica pesquisas realizadas referentes ao meio ambiente em geral. Um dos tópicos postados tinha o título: "TOP 10: PRINCIPAIS ONGS DE MEIO AMBIENTE NO BRASIL", o site elencou então os logotipos das 10 principais Organizações Não Governamentais que se dedicam especificamente à preservação do meio ambiente 
englobando âmbitos como as comunidades, patrimônios naturais, históricos e culturais do país. O website listou em seguida os resultados da pesquisa no qual nomeava e exemplificava brevemente cada uma das ONGs, e em seguida o site disponibilizou ainda a fonte utilizada para a pesquisa, na qual foi o website www.brasil.gov.br.

O método utilizado foi o da psicologia experimental, mais especificamente a psicofísica escalar embasada em Stevens (1975). Estes testes perceptuais possuem o objetivo de diagnosticar as percepções subjetivas que possuem grande relevância neste estudo. São inúmeras as possibilidades de testes possíveis deste método, mas para este estudo escolheu-se o de categoria. Ele é realizado por meio de uma escala ordinal, possibilitando a categorização e classificação dos logotipos, além de ordená-los de acordo com o resultado de cada atributo avaliado.

Essa escala, segundo Ferraz (2005) além de diferenciar subjetivamente os objetos analisados, também informa se ele tem mais ou menos qualidade nos atributos verificados.

Além de que, um segundo teste foi utilizado nesse estudo para complementar os resultados, nomeado de estimação de magnitude, que, segundo Ferraz (2005) é um processo de julgamento, em que os observadores emparelham números a diferentes níveis de sua própria impressão perceptiva, expressando assim uma razão à sensação atribuída.

O teste de percepção aplicado teve um público alvo específico direcionado a discentes e docentes do curso de bacharelado em Turismo da Universidade Estadual Paulista, considerando a relevância dos aspectos ambientais para este curso. Os pesquisados eram identificados apenas pelo nome, idade e sexo. A amostragem de sujeitos foi convencionada pelos pesquisadores como sendo relevante o número de 25 pessoas.

\subsection{Procedimentos}

Para aplicação dos testes utilizou-se os logotipos representados na reportagem, os 10 logotipos foram distribuidos aleatoriamente em uma folha de tamanho A4 para ser mostrada aos participantes. Estavam numeradas de 1 até 10 (1- 
SOS Mata Atlântica, 2- Recicloteca, 3- Ecoar, 4- Amazônia, 5- Ecoar, 6- Instituto Akatu, 7- WWF Brasil, 8- ISA, 9- Greenpeace, 10- Conservação Internacional- Brasil).

Figura 1: Logotipos das Ongs Ambientais Brasileiras

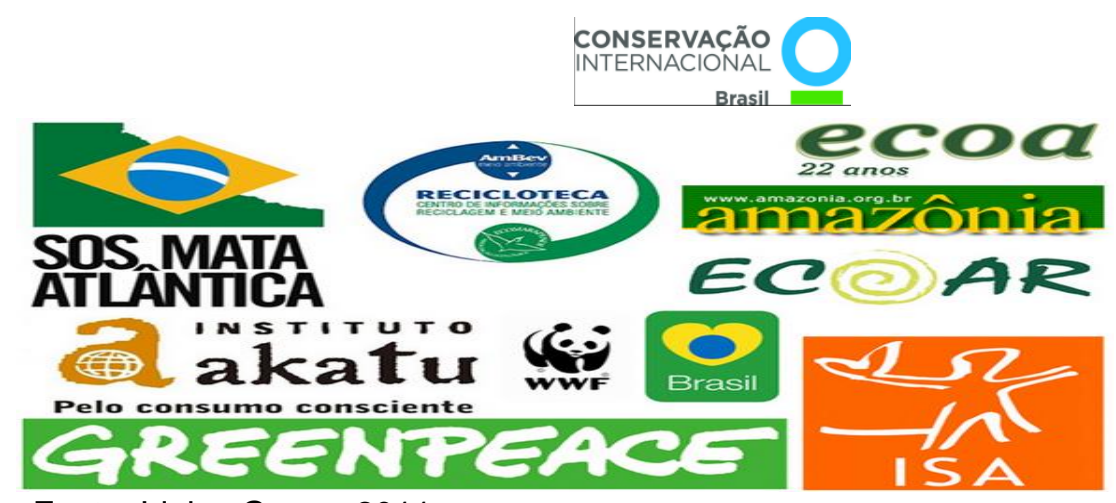

Fonte: Ideias Green, 2011.

Havia uma segunda folha com a ficha de aplicação, na qual os voluntários eram identificados, e em seguida continha uma tabela que deveria ser preenchida pelo sujeito, isso aconteceria de forma em que os 10 logotipos dispostos na primeira folha estivessem em uma mesa e abaixo a tabela para preenchimento. Perguntavase então qual dos logotipos seria o mais atraente na opinião do voluntário, após o apontamento perguntava-se qual seria o segundo mais atraente, e assim por diante até a décima posição. Esta situação ranqueou todos os logotipos conforme sua atratividade de acordo com o teste de categoria. Em seguida o mesmo procedimento foi realizado para a tabela referente à representatividade.

O segundo teste aplicado refere-se à magnitude que visou quantificar subjetivamente a intensidade da percepção de atratividade entre os logotipos. $O$ questionamento realizado foi: Quanto que o primeiro que você apontou como atrativo é mais atrativo que o segundo? Respondido isso se perguntou quanto é mais atrativo o segundo do terceiro? E assim por diante até se chegar do nono para o décimo, sendo que a esse ultimo foi designado o valor 0 . Após essa aplicação o mesmo procedimento foi realizado com o item representatividade, ou seja, qual é mais representativo e o quanto é mais representativo.

A ficha para aplicação dispõe o modelo da Figura 2: 
Figura 2: Modelo da ficha de aplicação

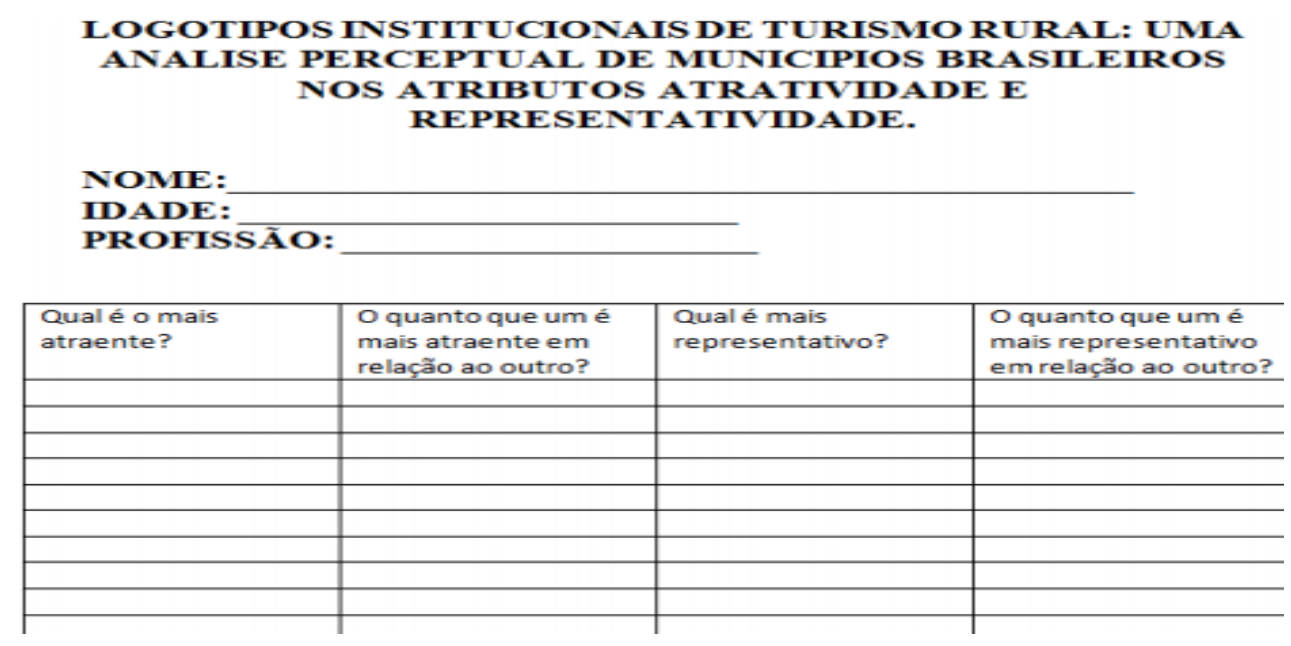

Fonte: Autores, 2015.

\subsection{Análises das informações}

Após a aplicação dos testes nos sujeitos participantes todas as informações numéricas foram repassadas para o software Excel for Windows da seguinte forma: Nas colunas horizontais foram inseridos em cada coluna os sujeitos sendo as células B a Z para os sujeitos (de 1 a 25). Nas linhas verticais foram inseridos os logotipos sendo que cada um ocupou uma linha utilizando a sequencia de células 5 a 14. E os logotipos foram representados pelos mesmos números utilizados na aplicação dos testes anteriores.

No teste de categorias onde ocorreu o ranqueamento foram dispostos a posição de cada logotipo apontada pelo sujeito, por exemplo, o logotipo 1 foi ranqueado em terceiro lugar pelo sujeito 5 então na linha referente ao logotipo 1 e na coluna referente ao sujeito 5 foi atribuído o número 3 que equivale a terceira posição no ranque.

Após esse procedimento ter sido realizado foram selecionadas todas as posições dispostas horizontalmente de cada logotipo e utilizou-se a ferramenta média para se calcular a média de posição de cada logotipo e se chegar ao resultado de qual logotipo foi considerado mais atraente e mais representativo pelos 
grupos, sendo que os logotipos que obtiveram o menor valor na média foram considerados os melhores ranqueados. Para melhor analisar os resultados também se utilizou a ferramenta DESVPAD do Excel para calcular o desvio padrão de cada logotipo.

Já no teste de estimação de magnitude, primeiramente somou-se todos os valores atribuídos do último colocado até o primeiro, chegando a um valor total, após essa soma foram subtraídos partindo do valor os apontamentos subsequentes e segundo valor para o terceiro até chegar-se ao último logotipo que possuía o valor 0 .

Na magnitude calculou-se a soma dos valores de todos os sujeitos do grupo, a média dos apontamentos de todos participantes bem como a posição no ranking de magnitude e o desvio padrão. Os dados foram qualitativamente relacionados chegando-se as considerações finais.

\section{RESULTADOS}

A primeira análise referente ao grau de atratividade entre os logotipos das ONGs teve como resultados números parecidos, entretanto o logotipo 9 da ONG Greenpeace teve a média inferior aos outros resultados, já a ONG número 10, Conservação Internacional - Brasil obteve o número maior de todas as outras. Conclui-se então que o Greenpeace obteve a primeira classificação e a Conservação Internacional - Brasil a última, ou seja, o logotipo 9 foi analisado pelos participantes como o mais atraente e logotipo 10 como o menos atraente.

A segunda análise foi a da representatividade que obteve números muito próximos nas somatórias das médias de cada logotipo, e uma das posições obteve média empatada, tornando a decisão pautada no desvio padrão. Nesta análise, a ONG Conservação Internacional - Brasil, obteve maior média, sendo considerada menos atraente e também menos representativa. Em relação a menor pontuação, a pesquisa mostrou que o logotipo número 1, SOS Mata Atlântica foi considerado o mais representativo. 
da Alta Paulista

Quadro 1: Resultados finais ranking

\begin{tabular}{|l|l|l|l|c|c|}
\hline Logotipos & \multicolumn{1}{|c|}{ ONGs } & $\begin{array}{l}\text { Média } \\
\text { Atratividade }\end{array}$ & $\begin{array}{l}\text { Média } \\
\text { Representativ } \\
\text { idade }\end{array}$ & $\begin{array}{l}\text { Média } \\
\text { Final }\end{array}$ & Posição \\
\hline 1 & 3,68 & 3,52 & 3,06 & $1^{\circ}$ \\
\hline 9 & $\begin{array}{l}\text { SOS Mata } \\
\text { Atlântica }\end{array}$ & 3,08 & 4,52 & 3,08 & $2^{\circ}$ \\
\hline 7 & Greenpeace & 4,68 & 3,68 & 4,18 & $3^{\circ}$ \\
\hline 8 & WWF Brasil & 4,56 & 4,92 & 4,74 & $4^{0}$ \\
\hline 4 & ISA & 5,92 & 5,88 & 5,09 & $5^{\circ}$ \\
\hline 5 & Amazônia & 5,00 & 5,84 & 5,42 & $6^{\circ}$ \\
\hline 6 & Ecoar & 6,00 & 5,88 & 5.94 & $7^{\circ}$ \\
\hline 3 & Instituto Akatu & 7,12 & 6,44 & 6,78 & $8^{\circ}$ \\
\hline 2 & Ecoa & 7,36 & 6,52 & 6,94 & $9^{\circ}$ \\
\hline 10 & Recicloteca & 6,62 & 8,00 & 7,31 & $1^{\circ}$ \\
\hline
\end{tabular}

Fonte: Autores, 2015.

Quadro 2: Resultados finais magnitude

\begin{tabular}{|c|c|c|c|c|c|}
\hline Logotipos & ONGs & $\begin{array}{c}\text { Media } \\
\text { Atratividade }\end{array}$ & $\begin{array}{c}\text { Media } \\
\text { Representativi } \\
\text { dade }\end{array}$ & $\begin{array}{l}\text { Média } \\
\text { Final }\end{array}$ & Posição \\
\hline 1 & $\begin{array}{l}\text { SOS Mata } \\
\text { Atlântica }\end{array}$ & 23,24 & 23,40 & 23,32 & $1^{0}$ \\
\hline 9 & Greenpeace & 26,00 & 21,76 & 23,08 & $2^{0}$ \\
\hline 7 & WWF Brasil & 18,28 & 22,60 & 20,44 & $3^{0}$ \\
\hline 8 & ISA & 18,64 & 16,00 & 17,32 & $4^{0}$ \\
\hline 5 & Ecoar & 19,08 & 15,44 & 17,26 & $5^{0}$ \\
\hline 6 & Instituto Akatu & 15,08 & 15,32 & 15,20 & $6^{\circ}$ \\
\hline 4 & Amazônia & 15,00 & 14,16 & 14,58 & $7^{0}$ \\
\hline 2 & Recicloteca & 9,64 & 12,12 & 10,88 & $8^{\circ}$ \\
\hline 3 & Ecoa & 9,88 & 11,72 & 10,08 & $9^{0}$ \\
\hline 10 & \begin{tabular}{|l|} 
Conservação \\
Internacional Brasil
\end{tabular} & 9,48 & 7,28 & 8,38 & $10^{\circ}$ \\
\hline
\end{tabular}

Fonte: Autores, 2015.

A soma das análises resultaram no quadro final da pesquisa, que ranqueia os logotipos de acordo com todos os atributos julgados.

Nos resultados referentes na magnitude da atratividade, quando maior ela fosse, melhor seria sua colocação, contraditoriamente do que acontece na análise 
da média. Desta forma, o logotipo 9 (Greenpeace) obteve a primeira colocação, e o décimo (Conservação Internacional Brasil) a última colocação. Neste caso, as ONGs resultantes como maiores e menores na magnitude da atratividade são de logotipos já vencedores nos primeiros ranqueamentos. Já os resultados da magnitude da representatividade relataram que o logotipo 1 (SOS Mata Atlântica) obteve a primeira colocação, e o logotipo 10 mais uma vez a décima colocação.

Quadro 3: Resultados finais

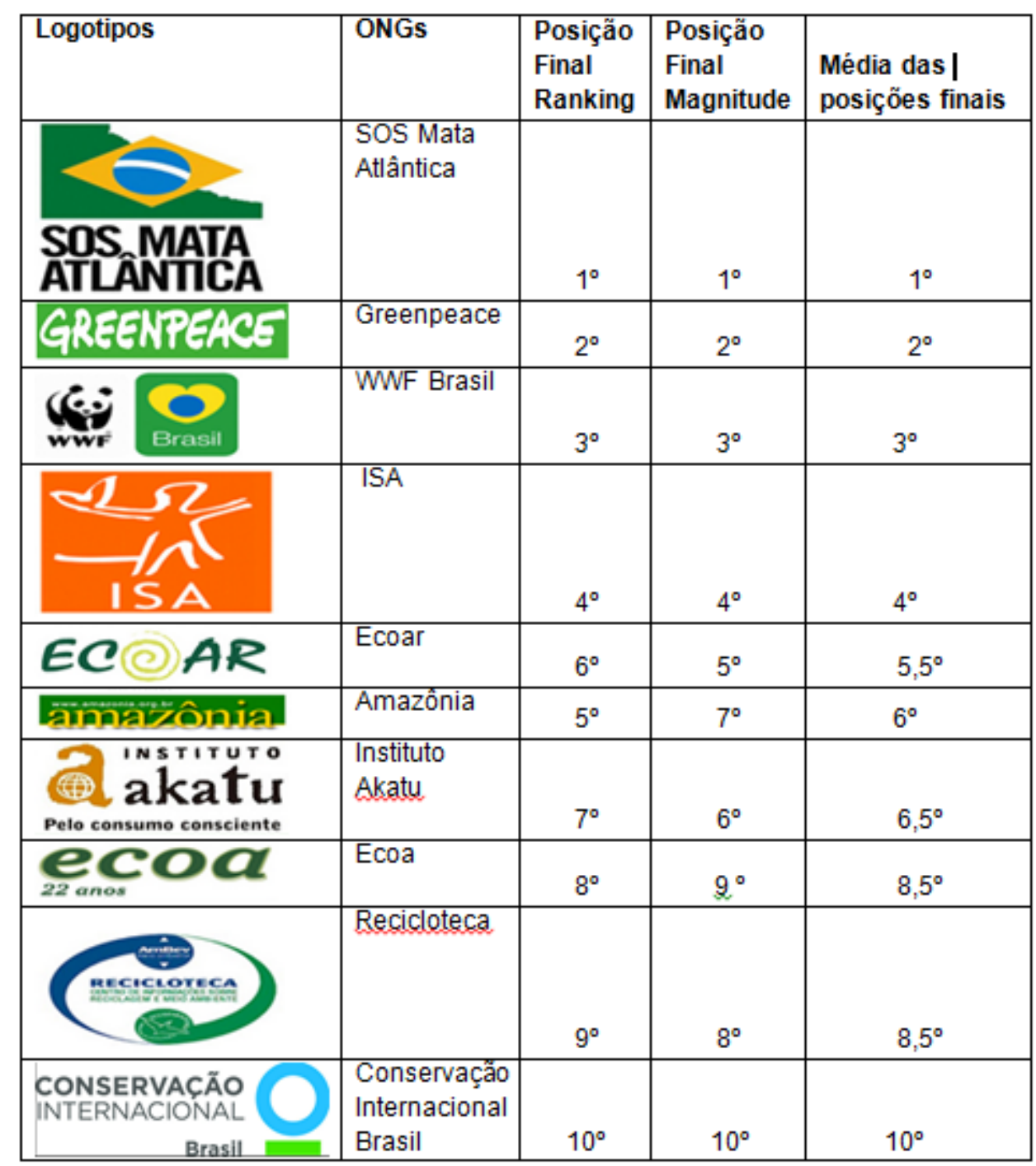

Fonte: Autores, 2015. 


\section{CONSIDERAÇÕES FINAIS}

Os quesitos atratividade e representatividade podem ser interpretados de diferentes maneiras, mas a pesquisa identificou que esses termos muitas vezes são confundidos pelos sujeitos, pois muitos deles julgaram ambos de forma parecida. $O$ que demonstra certa incoerência nos julgamentos, mas como são percepções subjetivas, os pesquisadores não podem influencia-los em suas respostas.

Essa situação é demonstrada por meio dos resultados finais, na qual as duas tabelas (representatividade e atratividade) mostram que em quase todos os casos a ordem na colocação não se altera, sendo que a mesma situação ocorre nas tabelas de magnitude.

Outro aspecto relevante que pode ser comparado é a influência em que os nomes das ONGs possuem em relação ao que foi julgado pelos participantes. $\mathrm{Na}$ primeira análise os resultados mostraram que o logotipo mais atraente foi o do Greenpeace, que notoriamente é uma das mais conhecidas em nível nacional e internacional. Ou seja, a percepção dessas pessoas em relação ao que é atraente não necessariamente refere-se ao desenho, a forma, ou as cores que foram utilizadas, e sim a confiança e o reconhecimento que a ONG já possui.

Sendo assim, o público universitário do turismo realizou um julgamento mais cognitivo e menos perceptual do logotipo, pois possuem conhecimentos prévios sobre a entidade, apesar de que perceptualmente o logotipo é muito simples, mas o nome Greenpeace que traduzido significa "paz verde" escrito em branco sobre um fundo verde é uma expressão linguística muito atraente e representativa, essas situações talvez justifiquem o julgamento positivo por parte dos sujeitos. Então, surge a pergunta: Será que o logotipo fez a ONG ser mais conhecida? ou as ações conhecidas da ONG faz com que seu logotipo seja melhor julgado?

Desta forma, pode se deduzir que os logotipos podem não ter sido submetidos a testes psicofísicos antes de sua divulgação, ou seja, a hipótese inicial parece ter sido comprovada. Esta situação poderia ser contrariada caso logotipos de ONGs menos conhecidas fossem julgadas como sendo mais atrativos e representativos. Se isso fosse comprovado, a representatividade e atratividade seriam advindas das percepções promovidas pelos logotipos, e não por meio de aspectos cognitivos pré-elaborados. 
A análise poderia ter resultados opostos se os logotipos não mostrassem qual ONG representam, mas na maioria deles o nome da ONG está explícito, tornando essa situação inviável. O mesmo pode ser percebido no resultado do logotipo 10 da conservação Internacional - Brasil, que foi considerado menos atraente e também menos representativo e ao mesmo tempo é menos conhecida que as ONGs ranqueadas nas primeiras colocações.

Já o logotipo da SOS Mata Atlântica foi considerado o mais representativo, e nos resultados gerais, obteve a primeira posição no ranque, isso talvez se justifique devido a ONG ser conhecida pelos sujeitos participantes por suas ações e comerciais de Televisão, e seu logotipo ser a bandeira do Brasil com a parte verde que segundo a cultura popular representa as florestas estar presumidamente devastada, o que gera uma percepção impactante e uma representatividade do problema ambiental do Brasil.

Nessa perspectiva esse trabalho pretendeu contribuir para que essa metodologia possa ser utilizada por futuras ONGs na elaboração de suas marcas visuais, obtendo uma melhor eficácia não somente nos atributos atratividade e representatividade, mas em qualquer outro que a instituição julgue ser importante para fidelização de sua imagem perante os diversos stakeholders que permeiam a sua relação.

\section{REFERÊNCIAS}

BARICK, H.; KOTLER, P. A Framework for Marketing Image Management. Sloan Management Review, v. 32, n. 2,1991.

BARONI, M. Ambiguidades e deficiências do conceito de desenvolvimento sustentável. Revista de Administração de Empresas. São Paulo, v.32, n.2, p. 14-24, abr./jun. 1992.

BURSZTYN, M.A; BURSTYN, M. Fundamentos de Política e Gestão Ambiental: caminhos para a sustentabilidade. Rio de Janeiro: Garamond, 2013.

COSTA, M.C.C, (Org.), Gestão da Comunicação: terceiro setor, organizações não governamentais, responsabilidade social e novas formasde cidadania, São Paulo: Atlas, 2006.

DIAS, G.F. A educação ambiental: valores humanos e estilos de vida sustentáveis. Boletim Informativo: desenvolvimento urbano e meio ambiente, ano 2, n.11, p. 02-03, jul./ago. 1993.

FERRAZ, M. A. A preferência pela prática de atividades físicas e esportivas: uma abordagem psicofísica. Tese de doutorado, apresentada à Faculdade de Filosofia, Ciências e Letras de Ribeirão Preto - USP, 2005.

FERREIRA, A. B. H. Novo Aurélio Século XXI: Dicionário Aurélio Básico da língua Portuguesa. 3 ed. Rio de Janeiro, RJ: Nova Fronteira, 1999. 
IDEIAS GREEN. Top 10: Principais Ongs de Meio Ambiente no Brasil. Disponível em: $<w w w$. ideiasgreen.com.br>. Acesso em: 03. jul. 2014.

IOSCHPE, E.B (Org.) et. al., 3 Setor: desenvolvimento social sustentado, Rio de Janeiro, Paz e Terra, 3. ed., Rio de Janeiro, 2005.

MARCONI, M. A.; LAKATOS, E. M. Fundamentos da metodologia científica. São Paulo: Atlas, 2009.

STEVENS, S. S. Psychophysic, New York: Wiley, 1975.

VIOLA, E.; LEIS, H. R. Desordem global da biosfera e a nova ordem internacional: o papel organizador do ecologismo. In: ANPOCS, Revista de Ciências Sociais Hoje, SP, Vértice/Ed.Revista dos Tribunais, 2008. 